\title{
An Empirical Study on HSR Demand Through Tourism Variables
}

\author{
DUAN Zenghui ${ }^{1,2}$ WANG Erda ${ }^{1}$ \\ 1. School of Management, Dalian University of Technology, Dalian Liaoning 116024, China; \\ 2. School of Applied Technology, Dalian Ocean University, Dalian Liaoning 116300, China
}

\begin{abstract}
The existence of HSR has gradually become an important indicator to judge the degree of development of a city. Under the conditions of limited budget and resources, how to choose the best suitable city? In order to answer these questions, this paper studied the impact of tourism on HSR, and sorted out the city pairs using multi-criteria decision analysis method, the ranking model and geographic information system technology. This paper considered the aspects of transportation, population, economy, location, distance, congestion and tourism, with the data of 36 Chinese cities above vice provincial level. The results show that it is helpful to effectively measure the impact of tourism on the high speed rail potential demand by adding a tourism variable in the ranking model. Of course, the role of tourism cannot be generalized, but it depends on the importance of tourism in the economic development.
\end{abstract}

\section{Keywords-MCDA; Tourism; HSR; City pair; GIS}

\section{INTRODUCTION}

In the recent two years, China has been in the key period for economic structure adjustment, with slow economic growth, and the tourism consumption growth against the trend, and it has become the new engine to stimulate economic growth. Meanwhile, High Speed Rail (hereinafter referred to as HSR) has become one of the important transportation means for the public, and also the important influencing factors of urban development and layout in sightseeing places. Convenient and fast HSR facilities can increase the attraction of sightseeing cities for tourists, and then promote the fast development of urban tourism industry. However, there have already had researches about the urban HSR development demand in China, and most of them focus on the macro economy of the state, especially on solving the pressure of staff mobility, expanding domestic and foreign market and other factors, or the research about the driving effect of urban HSR development on tourism [1-6], and few scholars systematically analyze the urban HSR demand of tourism. Thus, along with the fast development of domestic tourism, outbound and inbound tourism and Chinese tourists as well as the increasingly important function of HSR in this process, the discussion about the impact of tourism factors on urban HSR demand naturally has important theoretical and realistic significance.
Relatively speaking, the overseas researches about the relation between urban HSR and tourism were started earlier, and were mainly focused on the positive impact of HSR construction on tourist destination population, employment and urban accessibility. Chew pointed out that, high-level transportation infrastructure can make tourist destination more attractive, and it is the precondition for tourism development [7]. Prideaux thought that, sound transportation system can impact the type of tourists receiving at the sightseeing place [8]. Pagliara and Francesca thought that, traffic accessibility can impact the selection of tourists for tourist destination [9]. Masson and Petiot studied the impact of France Perpignan and Spanish Barcelona HSR on the tourism activities and economic development of the two cities, and obtained the conclusion that HSR can promote the development of tourism activities (especially commercial tourism and urban tourism) [10]. In 2008, Sean Randolph predicted the impact of HSR construction and no HSR construction at California Bay Area on the employment and population in 2030 through combining the data provided by the local railway bureau, and made comparison, and thought that HSR construction can promote the population increase and employment increase in the tourist destination along the line [11]. There are also many scholars holding different opinions; through studying the data of 50 Spanish areas in 15 years, Albalate and Fageda concluded that, the net impact of HSR on tourism was not always kept positive, for the occurrence of Spanish HSR decreased the flight frequency of airline, decreased seat quantity, and even forced some airlines to cancel; besides, HSR cannot generate enough power to offset these losses yet [12].

When being compared with overseas researches, the researches of Chinese scholars are relatively restricted, and the emphasis is the tourism regional space structure and layout aspects of HSR. WU Weiwei and SHI Xiaozhen used 20072012 tourist economic data of the National Day and Spring Festival, to analyze the tourist economic differences in cities connected through Beijing-Tianjin High-speed Inter-city Railway, Jinan-Qingdao High-speed Railway and BeijingShanghai High-speed Railway, and the analysis result held that, HSR made the regional tourist economic difference come closer to balance and stability, and put forward that it was requested to further promote HSR planning and construction speed[13]. GUO Jianke et al. studied and held that the opening of Harbin-Dalian High-speed Railway had promoted the accessibility of tourism traffic in northeast cities along the line and obviously promoted the tourist economic tie of northeast 
cities [14]. Through discussing the impact of WuhanGuangzhou High-speed Railway on the tourist space structure of Wuhan, LU Dongjiao obtained that the opening of HSR promoted the tourism development in Wuhan, expanded the space range of tourism domain, and promoted the space pattern recombination of tourism source market in Wuhan [15] LIU Ningning thought that the opening of HSR largely impacted the travel expectation and mode of tourists, changed the space pattern of tourism source market in sightseeing places along the line, and also promoted the attraction of the tourist destination [16].

To sum up, there are many researches about the impact of HSR on tourism at home and abroad, and they are mainly focused on the analysis about the driving effect of HSR on tourism, and can basically obtain consistent conclusion. Relatively speaking, there are few researches about the effect of tourism development on urban HSR development. Guirao and Soler investigated the impact of Spanish Toledo tourism on the new Toledo-Toledo HSR line, and they found out that tourism and sightseeing passengers occupy above $30 \%$ of the daily HSR passenger flow [17]. Guirao and Campa studied the positive effect of Spanish tourism on HSR [18]. Through using "the impact of tourism on HSR" as the key word to search academic papers on CNKI, there is no result related thereby. For this reason, this paper tries to apply Multi-criteria Decision Analysis (MCDA) on the basis of hierarchical ranking model, and then conducts the empirical research about the impact of Chinese tourism on urban HSR demand, and provides reference for the future HSR new route planning decision of Chinese cites and urban tourism development layout. The rest parts of the article include the following contents: Part 2 is the introduction of research method, Part 3 is the empirical research about the impact of tourism on HSR demand through using the relevant data about 36 cities above sub-provincial level in China and the data of railway department, and then Part 4 finally gave the research conclusion.

\section{RESEARCH METHOD}

\section{A. Multi-criteria decision analysis}

Multi-criteria decision analysis is a kind of decision analysis tool, and can provide the method for the evaluation and decision of a series of feasible schemes under multiple factors, multiple standards, and even the impact of mutual conflict factors [19]. Under relatively complicated conditions, such method can provide a modeling, organization and analysis took method with stronger operability to decision makers [20]. This paper will use MCDA method and then rank the urban HSR potential demands from several dimensions of transportation, population, position, distance, economy and travel, etc., and meanwhile, evaluate the impact of tourism on urban HSR potential demands.

\section{B. Hierarchical ranking model}

In 2009, Hagler and Todorovich put forward a model that can evaluate HSR potential demand market, and this paper introduces tourism variables[18], and then on the basis of MCDA frame, it establishes the hierarchical ranking model that can meet the actual conditions in China, and then measures the impact of tourism on HSR potential demands.

Firstly, assume that HSR potential demand can be measured with one ranking index (RI, Ranking Index); secondly, assume that RI value is mainly confirmed with the following six variables: including the transportation variable, population variable, position variable, distance variable, economic variable, and crowd variable. Firstly, respectively endow these six variables with certain weight, add them to the RI value equation (Equation (1)). The variable composition and assignment of such equation are obtained in combination with the actual conditions in China on the basis of the original equation put forward by Hagler and Todorovich. Calculate RI value of every two cities, and then rank the result, so as to obtain the pair of cities or city pairs with the most urgent HSR potential demands. Each city pair is constituted by two cities, and the population of cities is above 5 million, the distance of railway network between two cities is $160-800 \mathrm{~km}$, and it is the shortest path distance calculated on the basis of actual railway network. Table 1 has explained the variables in Equation (1).

$\mathrm{RI}=0.5(\mathrm{HRT}-\mathrm{S})+0.5(\mathrm{HRTM}-\mathrm{S})+(\mathrm{MAP}-\mathrm{S})+10(\mathrm{LCIM}-$ $\mathrm{S})+($ CITYP-S $)+($ MEGA-S $)+0.5($ HRT-E $)+0.5($ HRTM-E $)+$ $($ MAP-E $)+10($ LCIM-E $)+($ CITYP-E $)+($ MEGA-E $)+($ CL $)+$ (METRO-GDP)+ (TTI-IND) 
IMPLICATION ABOUT THE VARIABLES OF HIERARCHICAL RANKING MODEL

\begin{tabular}{|c|c|}
\hline Variables & Implication \\
\hline HRT-S & Subway of the starting city \\
\hline HRT-E & Subway of the ending city \\
\hline HRTM-S & Mileage for the subway of the starting city (mile) \\
\hline HRTM-E & Mileage for the subway of the ending city (mile) \\
\hline MAP-S & Population of the province where the starting city locates (ten thousand people) \\
\hline MAP-E & Population of the province where the ending city locates (ten thousand people) \\
\hline LCIM-S & Is the starting city the biggest city of the province where it locates? \\
\hline LCIM-E & Is the ending city the biggest city of the province where it locates? \\
\hline CITYP-S & Population of the starting city (ten thousand people) \\
\hline CITYP-E & Population of the ending city (ten thousand people) \\
\hline MEGA-S & Whether the starting city is located at super city agglomeration \\
\hline MEGA-E & Whether the ending city is located at super city agglomeration \\
\hline CL & Distance of city pairs (mile) \\
\hline METRO-GDP & Geometrical average for GDP per capita of the province where these two cities locate (USD) \\
\hline TTI-IND & Joint stroke time index of two cities in city pairs \\
\hline
\end{tabular}

In order to obtain the impact of tourism on urban HSR demands, this paper has added tourism variable $\mathrm{T}$, and assigned it with the weight of 10 , so as to balance the significance of population variables. Equation (1) has provided the hieratical ranking model adding tourism variable T. Recalculate RI value of city pairs meeting conditions as per Equation (2), and then obtained the ranking of city pairs with HSR potential demands considering tourism factors. And then it has compared and analyzed the ranking of city pairs calculated for two times, and obtained the impact of Chinese tourism on HSR potential demands.

$\mathrm{RI}=0.5(\mathrm{HRT}-\mathrm{S})+0.5(\mathrm{HRTM}-\mathrm{S})+(\mathrm{MAP}-\mathrm{S})+10(\mathrm{LCIM}-$ $\mathrm{S})+($ CITYP-S $)+($ MEGA-S $)+10(\mathrm{~T}-\mathrm{S})+0.5(\mathrm{HRT}-\mathrm{E})+0.5$ (HRTM-E) $+($ MAP-E $)+10$ (LCIM-E $)+($ CITYP-E $)+($ MEGA$\mathrm{E})+10(\mathrm{~T}-\mathrm{E})+(\mathrm{CL})+(\mathrm{METRO}-\mathrm{GDP})+(\mathrm{TTI}-\mathrm{IND})$

Although hieratical ranking model is not a kind of direct and accurate method for conducting empirical analysis about the impact of tourism on urban HSR, as can be seen from the currently domestic and overseas references and data, there hasn't been any more suitable mode yet to study this problem. Besides, the ranking of city pairs representing HSR potential demands can provide powerful reference to the relevant department considering the confirmation of new HSR plan. Which city pairs are suitable to build HSR? Which cities are not suitable? Which cities are in the most urgent to build HSR? Through the empirical research of this paper, it can at least provide certain references for decision makers to consider the aforementioned problems.

\section{EMPIRICAL RESEARCH}

This part adopts hieratical ranking model, and uses the annual data of the State Statistics Bureau Website, China Statistical Yearbook, 12306 China Railway Customer Service Center Website and other newest data sources on the basis of ARCGIS software technology, and 2016 National Railway Network Vector Data, to conduct the empirical analysis on the impact of Chinese tourism on HSR demands.

\section{A. Analysis on urban HSR potential demands based on hierarchical ranking model}

In consideration of the data accessibility and the practical significance of research result, the cities selected in this research include the provincial cities in China, the directcontrolled municipalities, sub-provincial cities, totally 36 cities. Then totally 25 cities for which the year-end population is above 5 million are selected among these 36 cities, and 300 city pairs can be constituted. Use ARCGIS software technology, calculate the distance of railway network for any one city pair, select city pairs for which the distance is within the range of $160-800 \mathrm{~km}$, totally 48 . As per the opinions put forward by Hagler and Todorovich in 2009, the range of 160 $800 \mathrm{~km}$ is the advantageous interval for HSR traffic (this mainly depends on the operation speed of HSR, and generally, it is held that 3-4h HSR travel is the most suitable), and this is basically consistent with the opinions of many domestic scholars [21-23].

As per Equation (2), calculate RI value for the aforementioned 48 city pairs, rank and obtain Fig. 1, and then the theoretical ranking of city pairs with Chinese HSR potential demands, and as for the city pair ranking the first, it represents that it has the maximum Chinese HSR potential 
demands at present, and is the city pair that is in urgent demand for building HSR. As can be seen from the result, the former 6 cities with the most population (above ten million), Chongqing, Shanghai, Chengdu, Beijing, Shijiazhuang and Tianjin rank top 10 in city pair ranking. Fig. 1 vividly shows the top 40 city pairs of RI value ranking in the railway network, and then divides them into four grades as per the ranking, and each grade includes 10 cities, which are marked with different colors and different thicknesses of lines. The thicker and deeper color lines represent those ranking top, i.e., HSR potential demand is more urgent; on the contrary, the thinner and lighter color lines represent those ranking behind, i.e., HSR potential demand is lower. As can be seen from Fig. 1 , HSR demand is mainly focused on Beijing-Tianjin-Hebei Region and Yangtze River Delta Region.

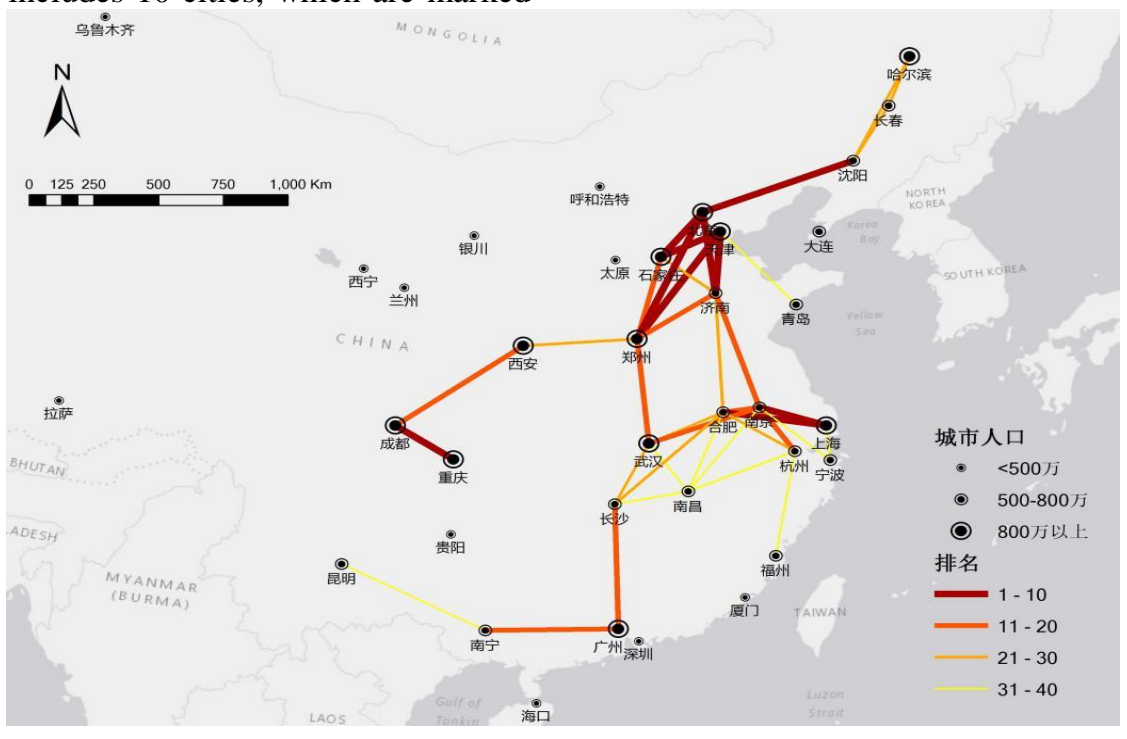

Fig. 1 The ranking results of HSR potential demands without considering the tourism variables

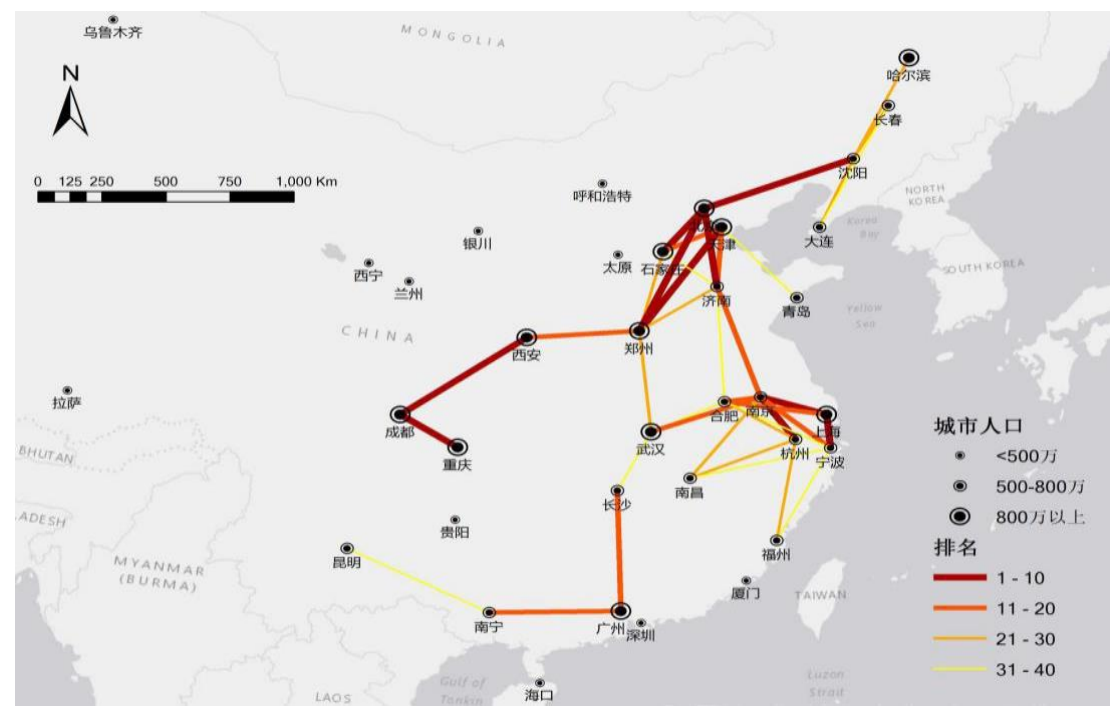

Fig. 2 The ranking results of HSR potential demands considering the tourism variables

\section{B. Analysis on the HSR potential demands considering tourism factors}

Since hieratical ranking model will be used to evaluate the impact of tourism factors on HSR potential demand, so this model requires a variable that can represent the tourism value of each city studied thereby. The tourism value for different cities is basically different, and this can depend on various factors, including people's preferences, and urban scale. As per the ranking of tourism value of cities studied thereby, confirm the different endorsements for the corresponding tourism variables of the city, and then use hieratical ranking model to evaluate the impact of tourism on HSR potential demand. Tourism variables are expressed with the tourism competitiveness level of Chinese cities. This paper selects the ranking result [24] of urban tourism competitiveness put forward by WANG Qiyan, the Executive Vice President of ITLIA and the Director for the Leisure Economy Research Center of Renmin University of China as well as Doctoral Student LUO Dong in 2010 to assign variable T. As per the ranking result, Beijing ranked the first, and the maximum tourism variable assignment was 3.0; Xiameng ranked the 
20th, and the assignment was 1.0; as per the ranking, other cities in the list were respectively assigned as 1.0-2.0; for cities that weren't ranked therein, the tourism variable $\mathrm{T}$ was assigned as 0.0 .

Add tourism variables to the model, and recalculate RI value for 48 city pairs as per Equation 2, and obtain the ranking statistics as shown in Fig. 1, which is similar to Fig. 1; divide the 40 cities ranked thereby into 4 grades, which will represent different HSR potential demands. Similarly, HSR demand shown in Fig. 1 is still mainly focused on BeijingTianjin-Hebei Region and Yangtze River Delta Region.

TABLE II. RANGE ABOUT THE RANKING CHANGE OF THE CITY PAIRS CONSIDERING THE TOURISM VARIABLES AND WITHOUT CONSIDERING THE TOURISM VARIABLES

\begin{tabular}{|c|c|c|c|c|c|c|c|}
\hline No. & Starting City & Ending City & Ranking Change & No. & Starting City & Ending City & Ranking Change \\
\hline 1 & Zhengzhou & Beijing & 0 & 21 & Zhengzhou & Xi'an & -10 \\
\hline 2 & Shijiazhuang & Beijing & 3 & 22 & Jinan & Shijiazhuang & 14 \\
\hline 3 & Shanghai & Nanjing & 0 & 23 & Hangzhou & Hefei & -1 \\
\hline 4 & Tianjin & Zhengzhou & 4 & 24 & Wuhan & Hefei & 14 \\
\hline 5 & Shanghai & Hefei & 7 & 25 & Jinan & Hefei & 14 \\
\hline 6 & Shijiazhuang & Tianjin & 8 & 26 & Changsha & Wuhan & 14 \\
\hline 7 & Jinan & Beijing & 0 & 27 & Harbin & Shenyang & 2 \\
\hline 8 & Chengdu & Chongqing & -4 & 28 & Changsha & Hefei & 13 \\
\hline 9 & Beijing & Shenyang & -7 & 29 & Changchun & Shenyang & 1 \\
\hline 10 & Jinan & Tianjin & 9 & 30 & Changchun & Harbin & 12 \\
\hline 11 & Nanjing & Hangzhou & -5 & 31 & Hangzhou & Fuzhou & -7 \\
\hline 12 & Nanjing & Hefei & 3 & 32 & Nanchang & Nanjing & -9 \\
\hline 13 & Guangzhou & Changsha & 4 & 33 & Ningbo & Shanghai & -23 \\
\hline 14 & Wuhan & Nanjing & 2 & 34 & Nanchang & Hangzhou & -7 \\
\hline 15 & Zhengzhou & Shijiazhuang & 10 & 35 & Nanchang & Wuhan & 8 \\
\hline 16 & Guangzhou & Nanning & 4 & 36 & Nanchang & Hefei & 8 \\
\hline 17 & Zhengzhou & Wuhan & 9 & 37 & Tianjin & Qingdao & -6 \\
\hline 18 & Jinan & Nanjing & 0 & 38 & Nanning & Kunming & -6 \\
\hline 19 & Chengdu & Xi'an & -10 & 39 & Changsha & Nanchang & 6 \\
\hline 20 & Zhengzhou & Jinan & 8 & 40 & Ningbo & Nanjing & -27 \\
\hline
\end{tabular}

Compare these two rankings, the ranking change of city pairs is collected as shown in Table 2. Zero ranking change indicates that there is no change to the city pair ranking, and positive ranking change indicates that the city pair ranking falls behind after considering tourism variables, for instance the ranking change of Shijiazhuang-Beijing city pair is 3, which indicates that, after considering tourism variable, the city pair ranking falls behind for 3 places. Correspondingly, negative ranking change indicates that the ranking is ahead, for instance, the ranking change for Chengdu-Chongqing city pair is -4 , which indicates that after considering tourism variables, the ranking is ahead for 4 places. The bigger the absolute value of ranking change is, the bigger the amplitude of ranking change will be. As can be seen from the ranking changes, after considering the impact of tourism variables, the top 5 city pairs with the biggest ranking increase amplitude include Ningbo-Nanjing, Ningbo-Shanghai, Chengdu-Xi'an, Zhengzhou-Xi'an and Nanchang-Nanjing (the increase amplitude is respectively 27,23,10, 10 and 9 places), except Nanchang, other cities rank top 20 considering urban tourism competitiveness. The top 5 city pairs with the biggest ranking decrease amplitude include: Jinan-Shijiazhuang, Wuhan-Hefei, Jinan-Hefei, Changsha-Wuhan and Changsha-Hefei (of which Jinan-Shijiazhuang, Wuhan-Hefei, Jinan-Hefei and ChangshaWuhan decrease for 14 places, and Changsha-Hefei decreases for 13 places). There is no city in the top 20 urban tourism competitiveness ranking list. Thus, it can be seen that, tourism variables can have certain impact on the urban HSR potential demands, and as for cities in the ranking list of urban tourism competitiveness, the higher the ranking is, the bigger the impact will be relatively, so it can be said that, the more developed the urban tourism is, the bigger the impact of tourism factors on HSR potential demands.

\section{CONCLUSION}

Under restricted capital and resource conditions, how to implement the strategic ranking of urban HSR construction and the impact and effect of tourism development on strategic ranking have become a research topic with important theories and practical significance. Thus, this paper selects multicriteria decision and analysis method, and through assigning multi-term criteria and multiple variables of different city pairs, on the basis of hierarchical ranking model, this paper conducts the ranking of RI value, and then confirms the ranking of HSR potential demands of cities, and then through adding tourism variables, it evaluates the impact of tourism on HSR potential demands. 
MCDA method is a process from the cognition of problems to the formation of final decision schemes, and such process includes 6 periods, i.e., confirming problems, selecting criteria, confirming options, confirming criteria weight, decision and sensitivity analysis[25]. The application of hierarchical ranking model is a relatively complicated process. This paper establishes the hierarchical ranking model meeting the actual conditions in China on the basis of the evaluation model design for the HSR potential demand in America conducted by Hagler and Todorovich in 2009 as well as the MCDA method established by Guirao and Campa, and it has conducted the empirical analysis about the impact of tourism development on urban HSR potential demands. In order to shorten the research range, this paper merely studies provincial cities, direct-controlled municipalities and subprovincial cities, and distance of city pairs merely considers $160-800 \mathrm{~km}$, and as for the tourism competitiveness ranking of cities, merely the former 20 cities are selected. According to the research result, tourism development has certain impact on Chinese HSR potential demands ranking, and after considering tourism factors, the increase amplitude about the ranking of HSR potential demand is also relatively big, and ranks relatively high, while cities with bigger decrease amplitude in ranking, tourism is generally undeveloped. These research conclusions can provide certain reference to the future HSR construction plan and development strategy adjustment in China. To sum up, tourism can exert certain impact on urban HSR potential demands, and it cannot be generalized. The bigger the contribution degree of tourism for the GDP increase in the target city is, the more developed the tourism will be, so when cities are conducting HSR construction plan, the tourism factors must be taken into consideration, vice versa.

\section{REFERENCES}

[1] YI Haifeng. Analysis on the Economic Integration of Northeast Region during "HSR Era" [J]. Enterprise Economy, 2013 (5): 143-146.

[2] WANG Yao and NIAN Meng. Can HSR drive regional economic development? [J].Shanghai Economic Research, 2014 (2): 82-91.

[3] LUO Shen and LIN Xiaoyan. Empirical Research about the Evaluation of HSR Impact on the Economy of Our Country [J]. Inquiry into Economic Issues, 2013 (11):74-78

[4] WANG Jianfeng and LI Zhigang. Empirical Analysis on the Impact of Shanghai-Hangzhou High-speed Railway on the Regional Economic Development along the Line [J]. Inquiry into Economic Issues, 2014 (9):74-77.

[5] LIN Xiaoyan, CHEN Xiaojun, BAI Yunfeng et al. Quantitative Analysis on the Regional Economic Impact of Beijing-Tianjin Inter-city Highspeed Railway [J]. Railway Economics Research, 2010 (5):5-11.

[6] ZHANG Yiyang. Research about the Impact of HSR on Regional Tourism Economic Development [D]. Hangzhou: School of International Trade in Economics, ZUFE, 2016.
[7] CHEW, J. Transport and Tourism in the Year 2000[J]. Tourism Management, 1987, 8 (2):83-85.

[8] PRINDEAUX, B. The Role of the Transportation System in Destination Development [J]. Tourism Management, 2000 (21):53-63.

[9] PAGLIARA, FRANCESCA. Proceedings of the Second International Conference of Traffic and Transport Engineering (ICTTE). [C].Serbia: University of Belgrade, 2014.

[10] MASSON, S, PETIOT, R. Can the High-speed Reinforce Tourism Attractiveness? The Case of the High-speed Rail between Perpignan (France) and Barcelona (Spain)[J]. Technovation, 2009, 29:611-617.

[11] WANG Degen, CHEN Tian, LI Li et al. Tourism Impact Research and Enlightment of Overseas HSR [J]. Geographical Science, 2012, 32 (3): 322-328.

[12] ALBALATE, D, FAGEDA, X. High speed rail and tourism: Empirical evidence from Spain [J]. Transportation Research Part A, 2016, 85: 174185.

[13] WU Weiwei and SHI Xiaozhen. Analysis on the "HSR Era" Tourism Economic Difference Based on Geographic Concentration [J]. Statistics and Decision, 2014, 24: 145-147.

[14] GUO Jianke, WANG Shaobo, LI Bo et al. Spatial Impact of HarbinDalian High-speed Railway on the Tourism Economic Tie of Northeast Cities [J]. Geographical Science, 2016, 36 (4): 521-529.

[15] LU Dongjiao. Research about the Impact of Wuhan-Guangzhou Highspeed on the Tourism Space Structure of Wuhan [D].Wuchang: The College of Urban \& Environmental Sciences, CUES, 2012.

[16] LIU Ningning. Research about the Impact of HSR on the Development of Tourism along the Line [D]. Dalian: School of History in Liaoning Normal University, 2014.

[17] GUIRAO, B, SOLER, F. Impacts of the New High-speed Service on Small Touristic Cities: the Case of Toledo. In: The Sustainable City V. Urban Regeneration and Sustainability [J]. Wessex Institute of Technology, 2008, 465-473.

[18] GUIRAO, B and CAMPA, J L. The Effects of Tourism on HSR: Spanish Empirical Derived from a Multi-criteria Corridor Selection Methodology [J]. Journal of Transport Geography, 2015, 47, 37-46.

[19] China Association for Geographic Information System GIS Theory and Method Specialized Committee. The 2nd Geological Cellular Automation and application Seminar Collected Papers [C]. Beijing: [the publisher is unknown], 2007.

[20] CATHY MACHARIS N, ANNALIA BERNARDINI. Reviewing the Use of Multi-Criteria Decision Analysis for the Evaluation of Transport Projects: Time for a Multi-actor Approach [J]. Transport Policy, 2015, $37,177-186$.

[21] XU Changle and XUN Yali. Regional Impact and Significance for the Arrival of HSR Era [J]. Resource and Environment of Yangtze River Basin, 2011, 20 (6): 650-654.

[22] XU Shenggang. Model Description and Application Research of HSR Competitiveness [D]. Beijing: School of Traffic and Transportation in Beijing Jiaotong University, 2014.

[23] XIAO Yun. Analysis on the Competitive Advantages of HSR and Air Passenger Transport [J]. Reformation \& Strategy, 2011, 27 (5): 136-138.

[24] WANG Qiyan and LUO Dong. Research about the Construction and Application of Urban Tourism Competitiveness Evaluation System in China [J]. Statistical Research, 2009, 26 (7): 49-54.

[25] ZHANG Hongxian, and YANG Qingsheng. Rural Tourism Development Layout and New Rural Construction Based on MCDA [J]. Human Geography, 2009 (3): 75-79. 